\title{
Agrobacterium-mediated transformation in medicinal trees
}

\author{
S. Mohana Priya, S. Indhu, R. Kalaiselvi and Rekha R. Warrier \\ Institute of Forest Genetics and Tree Breeding (IFGTB), P.B.No.1061, R.S.Puram, Coimbatore-641002, T.N., India
}

\section{Article Info}

Article history

Received 7 April 2020

Revised 1 June 2020

Accepted 3 June 2020

Published online 30 June 2020

Keywords

Agrobacterium

Transformation

Hairy roots

Medicinal trees

\begin{abstract}
Plant transformation relies on the bacteria Agrobacterium which has the potential to transfer genes of interest into a desired plant. The most commonly used species are A. tumefaciens and A. rhizogenes. This approach is convenient, especially in tree species, as conventional breeding takes a long time. It also helps to overcome other associated problems such as juvenility, heterozygosity, and incompatibility. The present review brings together research on Agrobacterium mediated genetic transformation in various medicinally important trees for production of secondary metabolites. Mostly the Agrobacterium mediated transformation aims at production of secondary metabolites in medicinal trees like Azadirachta indica, Semecarpus anacardium and Gmelina arborea, etc. More recent technologies are available with greater potential for gene manipulation. But they require an efficient transient transformation phase and successful regeneration protocols which is the key to future application of advanced technologies for improvement of medicinal trees.
\end{abstract}

Abbreviations: $\mathrm{A}_{600}$-Absorbance at $600 \mathrm{~nm}$; ACS-Acetosyringone; ATMT-A. Tumefaciens mediated transformation; BA-Butyric Acid; DKW1-Driver and Kuniyuki medium; GFP-Green Fluorescent Protein; IAA-Indole Acetic acid; IBA-Indole Butyric acid; KT-Kinetin; LB-Luria Bertani medium; NAA-Naphthalene Acetic Acid; npt II-neomycin phosphotransferase gene; hpt II-Hygromycin phosphotransferase gene; OD-Optical Density; rpm-revolutions per minute; RT-PCR-Real Time-Polymerase Chain Reaction; RT- qPCR-Real Time-quantitative Polymerase Chain Reaction; WPM-Woody Plant Medium; YEB-Yeast Extract Beef medium; YFP-Yellow Fluorescent Protein; YMB-Yeast Mannitol Broth; 2YT-Yeast extract and Tryptone media.

\section{Introduction}

Agrobacterium is a gram negative bacterium commonly found in the soil, non spore forming and causing rapid proliferation of cells in plants. The genus Agrobacterium belongs to the plant-associated bacteria, Rhizobiaceae, which also include nitrogen-fixing symbiotic bacteria. Initially, three species were described: A. tumefaciens, which induces crown galls on dicots; $A$. rhizogenes, which induces hairy root disease; and $A$. radiobacter, the avirulent strain. Some species-specific Agrobacteria, namely; A. vitis for grapevine, $A$. rubi for Rubiaceae members and A. larrymoorei from Ficus benjamina have also been isolated.

The Agrobacterium transfers a particular DNA segment, the T-DNA (transferred-DNA), into plant cells, which integrates into the plant chromosome (Figure 1a). Once, it is integrated stably into the plant genome, it triggers production of plant hormones to develop tumors

Corresponding author: Dr. Rekha R. Warrier

Scientist-F, Institute of Forest Genetics and Tree Breeding (IFGTB), P.B.No. 1061, R.S. Puram, Coimbatore-641002, Tamil Nadu, India E-mail: rekhawarrier@gmail.com

Tel.: +91-9442918647; +91-4222484167

Copyright (C) 2020 Ukaaz Publications. All rights reserved.

Email: ukaaz@yahoo.com; Website: www.ukaazpublications.com or multiple roots. It also produces opines which are sugar-amino acid conjugates that Agrobacterium catabolizes. This way, the bacterium creates its own niche for growth and proliferation. Agrobacteria catabolize a variety of metabolites and hence various strains are available. These opine stimulate bacterial conjugation thereby spreading the plasmid.

A. tumefaciens is the most commonly studied and used species in this genus. It is a rod shaped and soil borne bacteria causing infection through wounds in roots or crown in graft union regions. A. tumefaciens is widely exploited for foreign genes introduction into plants and has facilitated the development of many transgenic tree species (Harfouche et al., 2011). In order to obtain successful transgenic plants, via, A. tumefaciens, the main requirement is a robust organ regeneration and transformation system in the species (Mahender et al., 2012). A. tumefaciens-mediated transformation (ATMT) has many advantages such as flexibility in choosing the starting materials (cells, tissues, protoplasts, hyphae, spores or blocks of mycelia), high transformation efficiency and high frequency of single-copy T-DNA insertions (Abuodeh et al., 2000; de Groot et al., 1998). It can also be used to tag genes to explore cell type-specific gene expression and function, mutations, pathogenicity in bacteria and fungi (Betts et al., 2007).

Agrobacterium rhizogenes, similar to A. tumefaciens, is also used for introducing exogenous genes into plants. A. rhizogenes recognizes signal molecules expressed by wounded plant cells and produces a chemotactic response. The rhizogenic strains which contain a single copy of the Ri plasmid (Figure 1b) gets integrated into the plant chromosome leading to the formation of neoplastic, plagiotropic roots (hairy roots) caused by root-inducing genes rol $A$ to $D$ (Chilton et al., 1982). Hairy roots have the unique character of being able to grow in vitro in the absence of exogenous plant growth regulators (Collier et al., 2005). In addition, A. rhizogenes strains are also implied as genetic sources to produce new genotypes and phenotypes with high branching, wrinkled leaves, shortened 
internodes and modified flowering (Tepfer 1984). The wild-type A. rhizogenes strains have been used to improve rooting ability in woody species as T-DNA genes on Ri plasmid inûuence root system development (Tepfer, 1983).

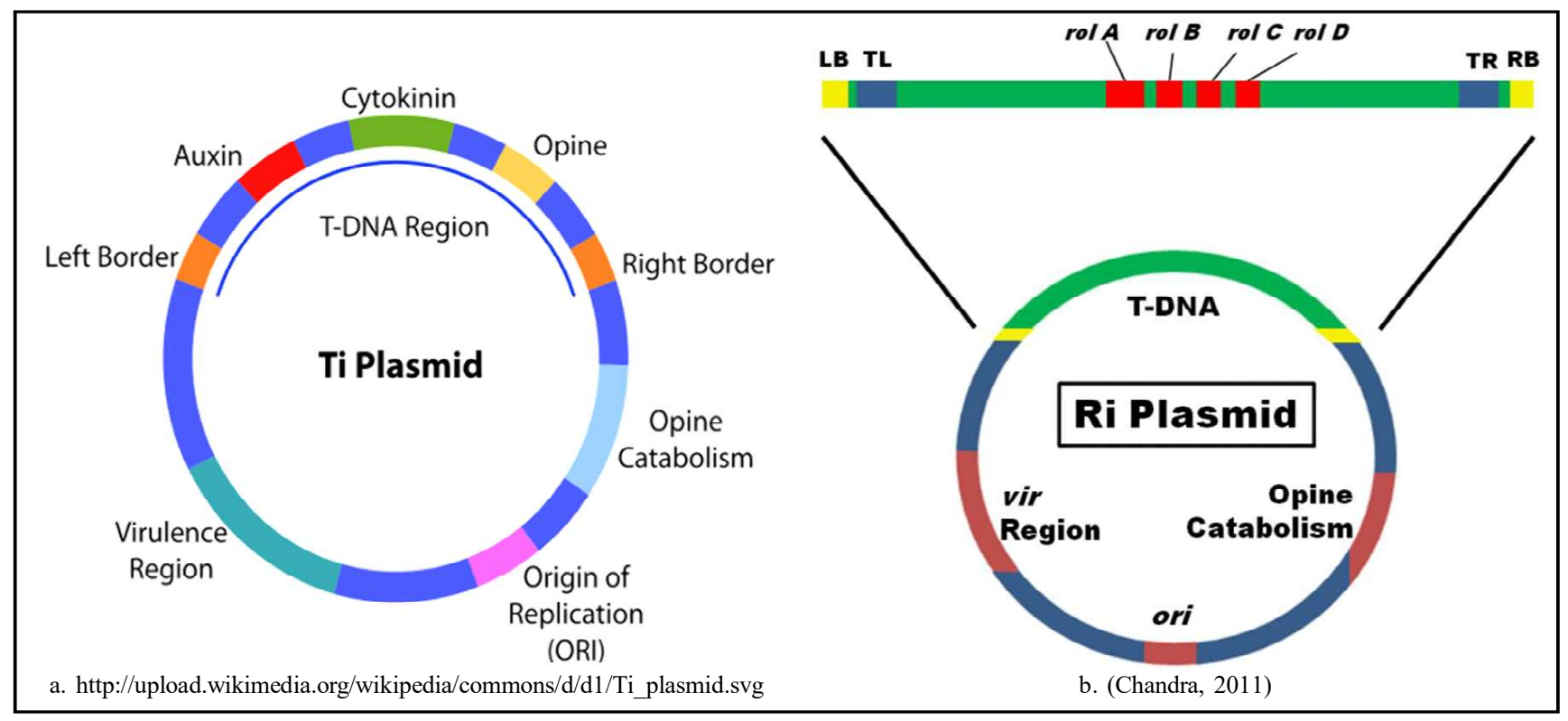

Figure 1: a. Ti and b. Ri Plasmids.

Many perennial trees have yielded therapeutic molecules for the treatment of many dreaded diseases like Taxol from Taxus spp. (for cancer treatment), quinine from Cinchona spp. (for malarial treatment) and aspirin from Willow (as analgesic). The high-value secondary metabolites in these trees are generally synthesized during the later stage of life and are produced in very less amount, not sufficient to meet the commercial demand. The continuously increasing demand of these metabolites has posed a great threat to the existence of many of these trees and has pushed many of them under different threat status. In the search for alternatives to production of desirable medicinal compounds from plants, biotechnological approaches, particularly, plant tissue cultures, are found to have great potential as a supplement to traditional agriculture (Rao and Ravishankar, 2002). Inconsistent yields coupled with instability of undifferentiated cell cultures initiated the efforts for development of new stable methods for enhanced production of secondary products, which led to hairy root cultures. Desired production of defined chemical products within carefully regulated, highly controlled microenvironment suspension cultures (Charlwood and Charlwood, 1991) were identified as the advantages of this technology. This method has become popular in the last two decades as the most popular method of producing plant secondary metabolites. In vitro regeneration of medicinal plants from various explants to enhance the production of secondary metabolites has led to high-quality plant based medicine (Birch, 1997). Today genetic transformation is used as a powerful tool for enhancing the production of novel secondary metabolites; especially by Agrobacterium rhizogenes induced hairy roots (Leena and Jaindra, 2003). Hairy roots have been found to be suitable for the production of secondary metabolites because of their stability and high productivity in hormone-free culture conditions. Some commonly used strains of $A$. rhizogenes are presented in Table 1.

Table 1: Commonly used strains of $A$. rhizogenes

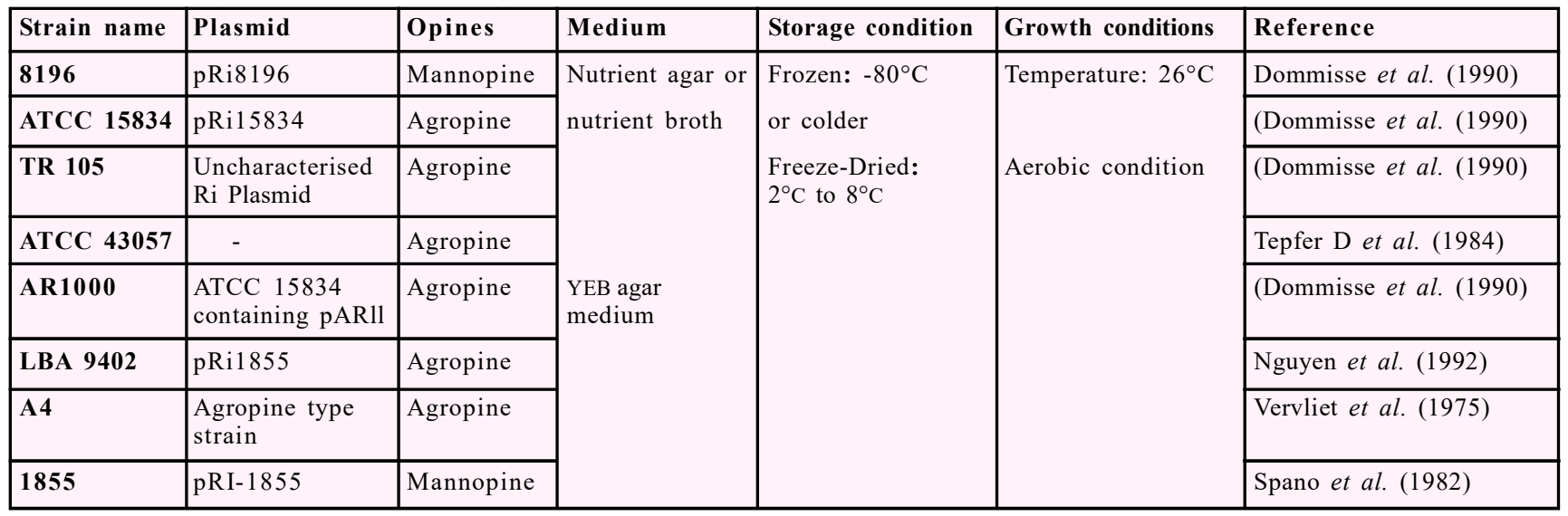




\section{Agrobacterium mediated transformation in medicinal trees}

Reports on induction of hairy roots and production of secondary metabolites are detailed below.

\subsection{Fagara zanthoxyloides}

Hairy roots of Fagara zanthoxyloides were obtained with the A. rhizogenes 9402 and a reduction of opine synthesis was observed. The infection produced numerous lateral branches, in both solid and liquid medium. The transformed roots produced the potent antileukemic fagaronine and the protein kinase $\mathrm{C}$ inhibitor chelerythrine, suggesting normal root metabolism. Bioefficacy was confirmed by studying the differentiation and growth inhibition of the K562 human erythroleukemic cells. Tryptophan and tyrosine regulated the chorismate mutase enzyme activity in the hairy roots (Couillerot et al., 2000).

\subsection{Henna (Lawsonia inermis)}

Lawsonia inermis (Lythraceae) hairy roots were developed using A. rhizogenes NCIB 8196 by Bakkali et al. (1997) using leaf segments in half strength MS media containing $0.5 \mathrm{~g} / 1$ of Claforan maintained at $25^{\circ} \mathrm{C}$ in the dark for 4 weeks. The pigment accumulation in hairy root cultures provides the possibility of independently studying morphological differentiation and biochemical differentiation. It is worth mentioning here, that root from whole plants were essentially lawsone-free. The hairy root cultures also accumulated $(+)$-catechin (1), 1, 2, 3, 6-tetra-O-galloyl- $\beta$-D-glucose (2) and 1, 2, 3, 4, 6penta-O-galloyl- $\beta$-D-glucose (3) and galloylglucoses.

\subsection{Taxus (Yew)}

Kim et al. (2009) found that the hairy root cultures were established in Taxus cuspidata (Korean yew) using R1000, A4, and 15384. The hairy root line RC 11106 was found to be the most appropriate. Methyl jasmonate induction accumulated $52.5 \mathrm{mg} / \mathrm{l}$ of taxol over 2 weeks of incubation at a 20-L culture scale (Han et al., 2000). Root formation in Taxus mairei induced by Agrobacterium rhizogenes (R1600, R1601, and R15834) revealed high 10-deacetylbaccatin (10-DAB) content in the roots (Chen et al., 2004).

\subsection{Cinchona officinalis}

Cinchona officinalis (Rubiaceae) leaves cocultivated with strain LBA 9402 produced quinine for one year (Geerlings et al., 1999). They also reported that hairy root lines of $C$. officinalis showed stable growth and morphology, and capacity of alkaloid production upto one year.

\subsection{Rauvolfia serpentina}

Ray et al. (2014) reported retention of stable phenotype of Ri-transformed root lines of $R$. serpentina over 3 years of in vitro culture. The phenotype of transformed root lines included creamish roots with a high degree of branching, plagiotropic growth, and devoid of extensive root hairs. Long-term stability of hairy root cultures of $R$. serpentina is also reported by Pandey et al. (2014) recording more than 6 years of in vitro culture. $R$. serpentina hairy roots (Ri-A4 transformed roots) produce considerably higher reserpine content than the normal roots after 10 weeks of growth. Ray et al. (2014) reported higher reserpine (approximately $3 \mathrm{mg} / \mathrm{g}$
DW) content in the LBA 9402 root lines. Pandey et al. (2014) reported the production of all three major terpene alkaloid in $R$. serpentina, namely reserpine, ajmaline, yohimbine; yohimbine concentration being highest followed by ajmaline and reserpine.

\subsection{Morus alba}

Three Agrobacterium rhizogenes strains were tested for the secondary metabolites (betulin and betulinic acid) production and transformation capacity of Morus alba L. All the tested strains of A. rhizogenes (R1601, LBA9402 and R1000) were able to induce hairy root formation in leaf tissue explants (Park et al., 2017). Result shows that betulin and betulinic acid production in hairy roots was found highest $(167.8 \pm 14.5 \mathrm{mg} /$ flask $)$ with strain LBA9402. Maximum production of betulin $(8.7 \pm 0.4 \mathrm{mg} / \mathrm{g})$ and betulinic acid $(4.1 \pm 0.2 \mathrm{mg} / \mathrm{g})$ was achieved with yeast extract and silver nitrate induction, respectively.

\subsection{Camptotheca acuminata}

Lorence et al. (2004) experimented the establishment of Hairy root cultures of $C$. acuminata by transformation of tissue with Agrobacterium rhizogenes strains ATCC 15834 and R-1000. The presence of rol genes in the plant genome that responsible for the hairy root phenotype was detected by southern blotting techniques. The hairy roots produced and secreted camptothecin (CPT) as well as the more potent and less toxic natural derivative, 10hydroxycamptothecin (HCPT), into the medium. Remarkably, the cultures were able to synthesize the alkaloids at levels equal to, and sometimes greater than, the roots in planta, i.e., 1.0 and $0.15 \mathrm{mg} / \mathrm{g}$ dry weight for CPT and the HCPT, respectively.

\subsection{Nothapodytes nimmoniana}

Chang et al. (2014) studied the hairy root induction in Nothapodytes nimmoniana by cocultivating te stem and leaf segments with AR281, AR1600, and ATCC15834. Results showed variation among A. rhizogenes strains and between $N$. nimmoniana clones in vitro. Strain ATCC15834 had the highest transformation ability. Three fast-growing hairy root lines were used for growth and alkaloid production. The growth index of hairy roots was 3 and camptothecin (CPT) produced was $0.0537-0.1555 \%$ dry weight (DW), after 40 days of culturing. Growth was faster in liquid than in solid medium $(9.8 \mathrm{mg} / \mathrm{l})$. Approximately $93.9 \%(9.2 \mathrm{mg} / \mathrm{l})$ of the total CPT produced was excreted into the culture medium.

\subsection{Azadirachta indica}

Azadirachta indica was transformed using Agrobacterium rhizogenes strain LBA920 (Srivastava, 2011). Hairy root inoculum (3 g/l dry weight) produced $13.3 \mathrm{~g} / 1$ after 25 days with an azadirachtin yield of $3.3 \mathrm{mg} / \mathrm{g}$ root biomass in the shakeflask experiments and in the batch cultivation the biomass production was $9.8 \mathrm{~g} / 1$ dry weight accumulating $2.8 \mathrm{mg} / \mathrm{g}$ azadirachtin biomass equal to volumetric productivity of $1.09 \mathrm{mg} / \mathrm{l}$ azadirachtin per day.

\subsection{Gmelina arborea}

Dhakulkar et al. (2005) experimented hairy root induction using the Agrobacterium strain ATTCC 15834. Six different hairy root lines with 32 per cent success were produced with unique transformation sequences. 


\subsection{Semecarpus anacardium}

In this species, optimization of the culture conditions and transformation frequency were studied by Panda et al. (2017) using Agrobacterium rhizogenes strain A4, ATCC15834 and LBA9402. The transformation resulted in hairy root initiation and 60 per cent transformation frequency was achieved in ATCC15834 strain. The other strains A4 and LBA9402 showed only 49 and 36 per cent transformation efficiency. PCR analysis confirmed the presence of gene specific primers $\operatorname{rolA}$, $\operatorname{rolB}$, rolC genes.

\section{Conclusion}

Genetic transformation can provide increased and efficient system for in-vitro production of secondary metabolites. This technique can be commercially exploited for secondary metabolites production through improved systems. The paper collates information on medicinal trees where this technology has been adopted for the production of secondary metabolites. Low success rate and recalcitrance of most species to transformation remains a major challenge for adoption of this technology in trees for production of the active principles. Once this challenge is overcome, it would be easier to adopt advanced technologies like trans-grafting, accelerated breeding, cis and intra genesis to explore production of new metabolites, and genome editing more frequently for enhancing metabolite production and providing quality medicine worldwide.

\section{Conflict of interest}

The authors declare that there are no conflicts of interest in the course of conducting the research. All the authors had final decision regarding the manuscript and decision to submit the findings for publication.

\section{References}

Abuodeh, R.O.; Orbach, M.J.; Mandel, M.A.; Das, A. and Galgiani, J.N. (2000). Genetic transformation of Coccidioides immitis facilitated by Agrobacterium tumefaciens. The Journal of Infectious Diseases, 181:2106-2110.

Bahari, Z.; Sazegari, S.; Niazi, A. and Afsharifar, A. (2020). The application of an Agrobacterium-mediated in planta transformation system in a Catharanthus roseus medicinal plant. Czech Journal of Genetics and Plant Breeding, 56(1):34-4.

Bakkali, A. T.; Jaziri, M.; Foriers, A.; Heyden, Y. V.; Vanhaelen, M. and Homes, J. (1997). Lawson accumulation in normal and transformed cultures of henna, Lawsonia inermis. Plant Cell, Tissue and Organ Culture, 51:83-87.

Betts, M. F.; Tucker, S. L.; Galadima, N.; Meng, Y.; Patel, G.; Li, L.; Donofrio, N.; Floyd, A.; Nolin, S.; Brown, D.; Mandel, M. A.; Mitchell, T. K.; Xu, J. R.; Dean, R. A.; Farman, M. L. and Orbach, M. J. (2007). Development of a high throughput transformation system for insertional mutagenesis in Magnaporthe oryzae. Fungal Genetics And Biology, 44:1035-1049.

Birch, R. G. (1997). Plant transformation: Problems and strategies for practical application. Annual Review of Plant Physiology and Plant Molecular Biology, 48:297-326.

Chandra, S. (2011). Natural plant genetic engineer Agrobacterium rhizogenes: Role of T-DNA in plant secondary metabolism. Biotechnology Letters, 34(3):407-415.

Chang, S. H.; Chen, H. F.; Tsay, J. Y.; Chen, J.; Huang, C. Y.; Lu, W. L. and Ho, C. K. (2014). Establishment of hairy root cultures of Nothapodytes nimmoniana to produce camptothecin. Taiwan Journal for Forest Science, 29(3):193-204.
Charlwood, B. V. and Charlwood, K. (1991). Methods in plant biochemistry, vol. 7, (B.V. Charlwood and D. V. Banthorpe, eds.) Academic Press, London, pp:43.

Chen, K.; Kuo, S. and Ho, C. (2004). Growth performance and taxane content of Taxus mairei cuttings with roots induced by Agrobacterium rhizogenes. Taiwan Journal of Forest Science, 19:133-142.

Chilton, M. D.; Tepfer, D. A.; Petit, A.; David, C.; Casse-Delbart, F. and Tempe, J. (1982). Agrobacterium rhizogenes inserts T-DNA into the genome of host plant root cells. Nature, 295:432-434.

Collier, R.; Fuchs, B.; Walter, N.; Kevin Lutke, W. and Taylor, C. G. (2005). Ex vitro composite plants: An inexpensive, rapid method for root biology. The Plant Journal, 43:449-457.

Couillerot, E.; Caron, C.; Trentesaux, C.; Chenieux, J. C.; Audran, J. C. (2000). Genetic transformation of Fagara zanthoxylaides Lam, (Rutaceae). In: Bajaj Y.P.S. (eds) transgenic trees. Biotechnology in Agriculture and Forestry, pp:44. Springer, Berlin, Heidelberg.

de Groot, M. J.; Bundock, P.; Hooykaas, P. J. and Beijersbergen, A. G. (1998). Agrobacterium tumefaciens-mediated transformation of ûlamentous fungi. Nature Biotechnology, 16:839-842.

Dhakulkar, S.; Bhargava, S.; Ganapathi, T. R. and Bapat, V. A. (2005). Induction of Hairy roots in Gmelina arborea Roxb and production of verbacoside in hairy roots. Plant Science, 169:812-818.

Domisse, E. M.; Leung, D. W. M.; Shaw, M. L. and Conner, A. J. (1990). Onion is a monocotyledonous host for Agrobacterium. Plant Science, 69:249-257.

Geerlings, A.; Hallard, D.; Caballero, A. M.; Cardoso, I. L.; Heijden, R. V. and Verpoorte, R. (1999). Alkaloid production by a Cinchona officinalis 'Ledgeriana' hairy root culture containing constitutive expression constructs of tryptophan decarboxylase and strictosidine synthase cDNAs from Catharanthus roseus. Plant Cell Reports, 19:191-196.

Han, K. H.; Gordon, M. P. and Floss, H. G. (2000). Genetic transformation of Taxus (Yew) to improve production of taxol. In: Bajaj Y.P.S. (eds) transgenic trees. Biotechnology in Agriculture and Forestry, Springer, Berlin, Heidelberg, 44:291-306.

Harfouche, A.; Meilan, R. and Altman, A. (2011). Tree genetic engineering and applications to sustainable forestry and biomass production. Trends in Biotechnology, 29:9-17.

Kim, J. A.; Baek, K. H.; Son, Y. M.; Son, S. H. and Shin, H. (2009). Hairy root cultures of Taxus cuspidata for enhanced production of paclitaxel. Journal of the Korean Society for Applied Biological Chemistry, 52(2): 144-150.

Leena, T. and Jaindra, N. T. (2003). Role of biotechnology in medicinal plants. Tropical Journal of Pharmaceutical Research, 2(2):243-253.

Lorence, A.; Bolivar, F. M. and Nessler, C. L. (2004). Camptothecin and 10hydroxycamptothecin from Camptotheca acuminata hairy roots. Plant Cell Reports, 22:437-441.

Ma, R.; Yu, Z.; Cai, Q.; Li, H.; Dong, Y.; Caldentey, K. M. O. and Rischer, H. (2020). Agrobacterium-mediated genetic transformation of the medicinal plant Veratrum dahuricum. Plants, 9:191.

Mahender, A.; Mallesham, B.; Srinivas, K.; Kumar, G. K.; Rao, K. V. and Rajesh, Y. (2012). A rapid and efficient method for in vitro shoot organogenesis and production of transgenic Bacopa monnieri $\mathrm{L}$. mediated by Agrobacterium tumefaciens. In vitro cellular and developmental biology. Plant, 48:153-159. 
Mehrotra, S.; Goel, M. K.; Rahman, L.U. and Kukreja, A. K. (2013). Molecular and chemical characterizationof plants regenerated from $\mathrm{Ri}$ mediated hairy root cultures of Rauwolfia serpentina. Plant Cell Tissue and Organ Culture, 114:31-38.

Nguyen, C.; Bourgaud, F.; Forlot, P. and Guckert, A. (1992). Establishment of hairy root cultures of Psoralea species. Plant Cell Reports, 11:424-427

Panda, B. M.; Mehta, J. U. and Hazra, S. (2017). Optimizing culture conditions for establishment of hairy root culture of Semecarpus anacardium L. 3 Biotech., 7:21.

Pandey, P.; Kaur, R.; Singh, S.; Chattopadhyay, S. K.; Srivastava, S. K. and Banerjee, S. (2014). Long-term stability in biomass and production of terpene indole alkaloids by hairy root culture of Rauvolfia serpentina and cost approximation to endorse commercial realism. Biotechnology Letters, 36:1523-1528.

Park, C. H.; Zhao, S.; Yeoa, H. J.; Park, Y. E.; Baska, T. B.; Arasu, M. V.; Al-Dhabib, N. A. and Park, S. U. (2017). Comparison of different strains of Agrobacterium rhizogenes for comparison of different strains of Agrobacterium rhizogenes for Morus alba. Natural Product Communications, 12(4):2017.

Rao, S. R. and Ravishankar, G. A. (2002). Plant cell cultures: Chemical factories of secondary metabolites. Biotechnology Advances, 20: $101-153$.
Ray, S.; Samanta, T.; Majumder, A.; Bandyopadhyay, M. and Jha, S. (2014). Cytogenetic characterization of Agrobacterium rhizogenes transformed root lines of Rauvolfia serpentina. Nucleus, 57:105112.

Spano, L.; Pomponi, M. and Tempe, S. (1982). Identification of T-DNA in the root inducing plasmid of the agropine type Agrobacterium rhizogenes 1855. Plant Molecular Biology, 1:291-304

Srivastava, S. and Srivastava, A. K. (2012). In vitro azadirachtin production by Hairy root cultivation of Azadirachta indica in nutrient mist bioreactor. Applied Biochemistry and Biotechnology, 166:365-378.

Tepfer, D. (1983). The potential uses of Agrobacterium rhizogenes in the genetic engineering of higher plants: Nature got there first. In: Lurquin P, Kleinhofs A (eds) Genetic engineering eucaryotes. Plenum Press, New York, pp:153-164.

Tepfer, D. (1984). Transformation of several species of higher plants by Agrobacterium rhizogenes, sexual transmission of the transformed genotype and phenotype. Cell, 37:59-967.

Vervliet, G.; Holsters, M.; Teuchy, H.; Montagu, M. V. and Schell, J. (1975). Journal of General Virology, 26:33-48.

Zhang, J.; Lin, M.; Chen, H. and Chen, X. (2017). Agrobacterium tumefaciens: mediated transformation of drumstick (Moringa oleifera Lam.) Biotechnology and Biotechnological Equipment, 31(6):1126-1131.

Citation: S. Mohana Priya, S. Indhu, R. Kalaiselvi and Rekha R. Warrier (2020). Agrobacterium-mediated transformation in medicinal trees. Ann. Phytomed., 9(1):27-31. http://dx.doi.org/10.21276/ap.2020.9.1.4 